\title{
O PROCESSO DECISÓRIO NO DESENVOLVIMENTO DE PRODUTOS EM ORGANIZAÇÕES COM MÚLTIPLOS INTERESSES THE DECISION-MAKING PROCESS IN PRODUCT DEVELOPMENT IN ORGANIZATIONS WITH MULTIPLE INTERESTS
}

\author{
Claudemir Bertuolo ${ }^{1}$ \\ Silvio Augusto Minciotti²
}

\section{RESUMO}

Diferente do que acontece nas empresas mercantis, a estrutura organizacional de uma cooperativa se caracteriza por uma gestão em que os associados desempenham simultaneamente diferentes papéis: proprietários, clientes, fornecedores, gestores e investidores sociais. Dentro deste ambiente de interesses diversos inerentes ao cooperado, analisa-se o processo de tomada de decisão para o desenvolvimento de produtos em uma cooperativa agroindustrial localizada no centro-oeste do estado de Goiás. O levantamento de campo coletou dados por meio de entrevistas semiestruturadas realizadas com oito executivos envolvidos diretamente com a tomada de decisão para desenvolvimento de produtos. Os resultados apontam que: (i) o processo decisório e o desenvolvimento de produto não são formalizados; (ii) as fases e etapas apontadas pela literatura não são seguidas e acontecem de maneira não estruturada, de acordo com as demandas momentâneas; (iii) o desenvolvimento de produtos não parte do planejamento estratégico; (iv) a orientação no mercado é para a venda, recaindo sobre a comercialização a responsabilidade pelo sucesso ou insucesso do produto.

Palavras-chave: Processo decisório. Desenvolvimento de produtos. Rotinas. Agronegócio. Cooperativa.

1 Doutor em Administração pela Universidade Municipal de São Caetano do Sul. Docente do curso de Administração da Universidade de Rio Verde (UniRV). E-mail: cbertuolo@uol.com.br.

2 Doutor em Administração pela USP - Professor do Programa de Pós-Graduação em Administração da Universidade Municipal de São Caetano do Sul (PPGA-USCS). E-mail: silvio.minciotti@uscs.edu.br. 


\begin{abstract}
Unlike mercantile companies, the organizational structure of a cooperative is characterized by a kind of management in which members play different roles simultaneously: owners, clients, suppliers, managers and social investors. Within this environment of diverse interests inherent to the members of the cooperative, we analyzed the decision-making process for product development in an agroindustrial cooperative located in the mid-west of the state of Goiás. The field survey collected data through semi-structured interviews carried out with eight executives directly involved in decision-making for product development. The results show that: (i) the decision-making process and product development are not formalized; (ii) the phases and stages pointed out in the literature are not followed and happen in an unstructured way, according to momentary demands; (iii) product development does not start from strategic planning; (iv) market orientation is for sale, and the responsibility for the success or failure of the product falls on commercialization.
\end{abstract}

Keywords: Decision-making process. Product development. Routines. Agribusiness. Cooperative.

\title{
1 INTRODUÇÃO
}

As empresas competem em ambientes ambíguos e duvidosos e isso demanda, entre outras variáveis, que as decisões frente ao desenvolvimento de produtos sejam rápidas e acertadas no sentido de garantir melhor posicionamento no mercado (WHEELWRIGHT; CLARK, 1994). Para Davila (2000), o processo de desenvolvimento de novos produtos (DNP) é pouco seguro e nisso reside a necessidade de uma linha sequencial capaz de permitir como que um script para ajudar a tomada de decisão.

Se estas realidades se impõem para empresas mercantis produtoras de bens, são ainda mais imperiosas para as cooperativas que se constituem, na definição de Lengler, Lago e Coronel (2007), como uma sociedade civil/comercial sem fins lucrativos, cuja finalidade é viabilizar e desenvolver atividades de consumo, produção, crédito, prestação de serviços e comercialização; atuar no mercado gerando benefícios para os cooperantes e formar e capacitar seus integrantes para o trabalho e a vida em comunidade. Barrreiros, Protil e Moreira (2008) lembram ainda que essa forma de associação apresenta características peculiares em sua constituição legal que influenciam a adoção de princípios e doutrinas que exercem significativos reflexos na sua estruturação e governança organizacionais, delegação e exercício de poder e consequentemente na forma como ocorre o processo decisório. Lembram ainda que o poder nas cooperativas é desempenhado de maneira igualitária, diferente das demais empresas nas quais o poder é estabelecido pela proporcionalidade do capital.

Outro fator a destacar é o relacionamento ambíguo presente no sistema cooperativista, já que os cooperados exercem as funções de clientes, fornecedores, proprietários da associação (BARREIROS; PROTIL; MOREIRA, 2008), investidores sociais e, por vezes, são os próprios gestores. Neste emaranhado de papéis, surgem conflitos nos interesses, o que acaba interferindo ainda mais no processo de decisão sobre o DNP, quando comparado a outros tipos de empresas.

Para tanto, o objetivo do trabalho é identificar como acontece o processo de decisão no DNP em uma cooperativa agroindustrial localizada no centro-oeste do estado de Goiás, considerando que 
estas organizações se diferenciam das demais empresas mercantis pelo tipo de sociedade de capital e gestão. Para dar conta da proposta, foi realizada uma pesquisa qualitativa no mês de agosto de 2016, por meio de entrevista semiestruturada, com oito executivos da cooperativa.

O trabalho oferece uma contribuição à área da Administração, à medida que permite aprofundar, com base na literatura, como acontece a tomada de decisão no DNP em cooperativa tendo em vista que os associados têm múltiplos interesses nos resultados que, por vezes, se mostram contraditórios. $\mathrm{O}$ artigo contempla uma fundamentação teórica sobre processo decisório e DNP, descreve a metodologia, apresenta a análise e discussão dos resultados, fechando com as considerações finais em que se apontam oportunidades para novos estudos em relação ao tema.

\section{REFERENCIAL TEÓRICO}

\subsection{PROCESSO DECISÓRIO}

O termo "processo decisório", de acordo com Mintzberg, Raisinghani e Théorêt (1976), contempla um conjunto de atitudes e movimentos desencadeados a partir de um estímulo, fechandose o ciclo com o comprometimento para a ação. Vários pesquisadores dedicaram-se ao estudo e mapeamento do processo decisório no dia a dia das organizações (BETHLEN, 1987; BATAGLIA, 2002) e observa-se que dependendo do embasamento metodológico, esses modelos podem ser classificados como normativos ou descritivos (BATAGLIA, 2002).

A teoria de decisão normativa tem suas bases na economia e na matemática e contempla estudos referentes a "como as decisões devem ser tomadas". Segundo essa vertente, o indivíduo é racional e só decide mediante escolha de ações ou alternativas. Já a teoria descritiva, que se pauta nos estudos da psicologia e da administração, baseia-se em entender "como as decisões são realmente feitas", preocupando-se em descrever como o indivíduo se comporta em determinadas situações (REIS; LOBLER, 2012). Em outras palavras, os autores defendem que se, por um lado, a teoria normativa refere-se ao "modo como o ser humano idealizado, racional, superinteligente, deve agir" (REIS; LOBLER, 2012, p.4) sob a análise da coerência e da racionalidade, capturadas geralmente em termos de axiomas, por outro lado, a teoria descritiva relaciona-se a "como o indivíduo pensa e se comporta e a como os indivíduos aprendem e modificam seu comportamento" (REIS; LOBLER, 2012, p.4).

Especificamente em relação ao objeto de estudo proposto - processo decisório no DNP no ambiente de uma cooperativa de agronegócios -, as colocações da teoria descritiva sobre "como as decisões são realmente feitas" são oportunas. E, dentro dessa vertente, toma-se como suporte teórico as construções da teoria descritiva de Mintzberg, Raisinghani e Théorêt (1976), considerada seminal na literatura de modelos de tomadas de decisão com enfoque administrativo, por meio da obra “The Structure of 'Unstructured' Decision Processes". O referido trabalho se concentra nas teorias administrativas com abordagem estratégica e defende que há uma estrutura implícita aos processos de decisão, consideradas por eles como "não estruturadas". Essas "estruturas não estruturadas" referemse aos processos de decisão que não tenham sido encontrados exatamente da mesma forma nas diversas vezes em que foram estudados e para os quais não existe um conjunto predeterminado e explícito de 
respostas ordenadas na organização. O modelo de Mintzberg et al. (1976) é utilizado neste trabalho por contemplar estas "estruturas não estruturadas"; entende-se que esse modelo é perfeitamente aplicável ao ambiente de estudo e, ainda, como diz Choo (2003), por ser um padrão que dá destaque à tomada de decisão em ambientes complexos como o da cooperativa que lida com associados com múltiplos interesses.

O modelo do processo decisório estratégico proposto por Mintzberg, Raisinghani e Théorêt (1976) foi descrito em termos de três principais fases: i) Identificação: estímulo inicial do processo, mobilização dos recursos e rotina de diagnóstico; ii) Desenvolvimento: compreende a procura por alternativas de ação e o processo de construção da decisão; iii) Seleção: relacionada à rotina de julgamento das alternativas originadas na fase de desenvolvimento, eliminando aquelas que são desnecessárias à avaliação da decisão, especialmente para as decisões tomadas por um único indivíduo. Corresponde, ainda, à aprovação ou rejeição de propostas que seguem um nível hierárquico superior quando necessitam de uma aprovação para serem autorizadas.

Dando suporte às principais fases, tem-se: i) rotina de decisão, que compreende o modo como o decisor executa as etapas, como é feito seu planejamento e como aloca os recursos organizacionais; ii) rotina de comunicação, que se refere à exploração (busca geral da informação), investigação (buscas e pesquisas específicas) e disseminação (divulgação do andamento) das informações essenciais para a tomada de decisão; iii) rotina política, que envolve a influência de indivíduos que procuram satisfazer os interesses pessoais por meio do processo decisório.

Com todas estas fases e rotinas, Mintzberg, Raisinghani e Théorêt (1976) defendem que os processos de decisão estratégica são complexos e dinâmicos, passíveis de estruturação conceitual, mas incapazes de serem lineares, portanto cíclicos, cabíveis de voltarem às etapas antecedentes, revisando-as e gerando novos rumos para a decisão.

O processo decisório, quando aplicado ao DNP, torna-se ainda mais intricado e dinâmico porque se junta às outras diversas fases e etapas presentes no desenvolvimento de produtos. Considera-se também a complexidade da decisão diante do fato dos cooperados terem interesses múltiplos durante os estágios que acompanham a decisão e quanto aos resultados dessa.

\subsection{DESENVOLVIMENTO DE NOVOS PRODUTOS (DNP)}

O cenário de competitividade e incerteza, em que as rápidas e corretas decisões tendem a levar as empresas ao sucesso, exige também novos produtos e serviços que atendam às necessidades e desejos dos consumidores. Para Costa e Jongen (2006), o DNP, formatado a partir do entendimento do mercado e dos indivíduos envolvidos nele, garante vantagem competitiva para as empresas.

Quanto aos procedimentos, Ulrich e Eppinger (2000) entendem que o DNP tem início com a verificação das oportunidades e finaliza com a produção, comercialização e entrega do produto. Para Mattar e Santos (2003), o processo de DNP pode ser definido como um plano formal, mapa de rota que vai desde o mapeamento das oportunidades, testes, produção, acompanhamento e ajustes, sempre precedidos por um ponto de decisão. O objetivo de um projeto e/ou processo de DNP é transformar uma prospecção de mercado em um produto que atenda às necessidades dos clientes de uma maneira economicamente viável e real. 
Peters et al. (1999) afirmam que há diversos padrões para o DNP, cada qual refletindo o entendimento de pesquisadores a partir de suas experiências. Mattar e Santos (2003, p. 320) indicam que não há "um padrão único para a estruturação do processo de desenvolvimento de novos produtos". Apesar da existência dos diversos modelos disponíveis, Rozenfeld et al. (2006) destacam a importância da empresa ter um modelo sistematizado e documentado de cada etapa do processo, fundamentalmente para dar visibilidade aos públicos que interagem com a organização, e também para que os funcionários possam trabalhar dentro de uma rotina padrão.

Para este trabalho, optou-se pelo padrão de DNP de Rozenfeld et al. (2006) por se entender que o modelo proposto por eles é uma síntese das diversas fases e etapas descritas na literatura. Ainda, segundo Faccio et al. (2010), é um modelo mais completo, contemplando claramente três fases bem delineadas, desenvolvido por pesquisadores nacionais e muito utilizado na academia.

Rozenfeld et al. (2006) oferecem um processo de DNP divididos em pré-desenvolvimento, desenvolvimento e pós-desenvolvimento. Dentro dessas três macrofases, encontram-se outras etapas, atividades e tarefas. No pré-desenvolvimento estão o (i) planejamento estratégico de produtos - contempla as informações estratégicas corporativas no plano estratégico de produtos e o (ii) planejamento do projeto - inicia com a determinação do escopo e planejamento do projeto macro e finaliza com o projeto específico. Nesta macrofase, acontece a coleta de informações tecnológicas, comercial e financeira, no âmbito organizacional.

Uma vez definido o portfólio de produtos e realizado o planejamento dos projetos, temse a segunda macrofase: desenvolvimento. Nessa etapa, estão presentes as fases do (i) projeto informacional, (ii) projeto conceitual, (iii) projeto detalhado, (iv) preparação para a produção e o (v) lançamento do produto. O projeto informacional contempla as principais decisões de projeto a partir dos requisitos do cliente do produto, de fornecedores e ciclo de vida dos produtos. O projeto conceitual abarca a concepção do produto, definida na etapa informacional e trata de elementos como layout, estilo do produto e processo de fabricação. O projeto detalhado oferece os desenhos e minúcias para a produção. Na preparação para a produção, estão presentes o planejamento para a produção do lote inicial e sua avaliação, sendo aplicadas ações corretivas, se necessário. O final da macrofase de desenvolvimento acontece com o lançamento do produto, o que demanda mobilização da equipe de vendas, distribuição, assistência técnica e marketing. A etapa de desenvolvimento faz uso das informações técnicas para a produção e comercialização do produto considerando os protótipos aprovados, testes, capacidade de instalações e os recursos para a comercialização.

Por fim, dentro das macrofases descritas por Rozenfeld et al. (2006) está o pós-desenvolvimento. Esta fase compreende o acompanhamento do produto quanto à necessidade de modificações e desempenho, bem como, se justificada, a retirada do produto do mercado.

Observa-se que o processo de DNP estrutura-se sobre uma ordenação de atitudes e atividades com início, meio e fim bem delineados e que estão à disposição das organizações para torná-las mais rápidas diante das necessidades de mercado. Neste modelo, é preciso articular competências para que as decisões sejam acertadas em cada fase do desenvolvimento a fim de que o output gere valor competitivo. No caso específico de uma cooperativa, é imperioso compreender as interfaces presentes nos diversos entroncamentos que exigem decisão para o DNP, uma vez que os atores envolvidos desempenham díspares papéis durante todo o processo de concepção e decisão para o lançamento de novos produtos. 


\section{METODOLOGIA}

O ambiente de pesquisa foi definido pela importância que as cooperativas têm no setor de agronegócios, à medida que as propriedades rurais perderam sua autossuficiência e passaram a depender de produtos e serviços de terceiros, sendo, acima de tudo, obrigadas a se especializar e enfrentar a globalização (BATALHA et al., 2005). É a partir dessas percepções e mudanças no setor que surgem as associações e cooperativas agroindustriais para auxiliarem os produtores rurais na solução de seus problemas técnicos, mercadológicos, de recursos humanos e ambientais (BILIBIO, 2009).

Para atender aos objetivos do trabalho, escolheu-se para estudo uma cooperativa localizada no centro-oeste do estado de Goiás, em função da sua importância no setor do agronegócio. O balanço de 2013 da cooperativa aponta um quadro com mais de dois mil funcionários, cerca de seis mil cooperados e faturamento de 2,5 bilhões de reais. A cooperativa está presente em 12 municípios e conta com lojas agropecuárias, armazenagem, revenda de máquinas e implementos, cooperativa de crédito, centro tecnológico e um complexo industrial com seis indústrias: óleo, farelo de soja, lacticínios, rações, fertilizantes e sabão.

De acordo com o ranking das 1000 maiores empresas, publicado pelo jornal Valor Econômico, em parceria com a Serasa Experian e a Fundação Getúlio Vargas (FGV-SP), com dados fechados também em 2013, a cooperativa objeto de estudo ocupa a posição 211, com receita líquida de $\mathrm{R} \$$ 2.383.7 milhões. Dentro do setor agropecuário é a $3^{\mathrm{a}}$ colocada, considerando-se a pontuação total dos critérios: Receita líquida, Margem Ebitda, Crescimento sustentável, Rentabilidade, Margem da atividade, Liquidez corrente, Giro do ativo, Cobertura de juros (VALOR ECONÔMICO, 2014).

Para compreender o processo decisório no DNP da cooperativa, fez-se uso da metodologia qualitativa por entender ser esta capaz de fornecer informações sobre o fenômeno a partir da exploração e descrição das percepções (CRESWELL, 2010). Conforme o autor, trata-se de um levantamento de campo qualitativo que visa obter informações que representem a população analisada de forma ampla, estudando o fenômeno em seu ambiente natural.

O levantamento dos dados foi realizado no mês de outubro de 2016, por meio de entrevistas com roteiro semiestruturado de perguntas, conectadas ao referencial teórico para garantir consistência ao estudo. A seleção dos entrevistados deu-se pela indicação da diretoria geral da cooperativa, tendo por referência a relação direta que mantêm com o processo de decisão para lançamento de produtos. A amostra foi composta por um superintendente da área comercial e seus três gerentes de vendas que respondem pelos setores de soja, ração e leite, um superintendente da área industrial e três de seus quatro gerentes, que atuam nos setores de ração, laticínios e fertilizantes, totalizando oito entrevistados. Quanto ao número de entrevistas, Patton (2002) afirma não existirem normas específicas, ficando a definição atrelada ao que se pretende saber, a finalidade do estudo e sua utilidade. No caso deste trabalho, as respostas dos oito entrevistados demonstraram a saturação e redundância das informações, não resultando em outras contribuições dentro da análise pretendida (GODOI; MATTOS, 2006). A tabela 1 identifica o tempo de empresa de cada um deles. 
Tabela 1: Tempo de empresa dos entrevistados

\begin{tabular}{ll}
\hline Entrevistado & Tempo de Empresa \\
\hline Entrevistado 1 & 35 anos \\
\hline Entrevistado 2 & 21 anos \\
\hline Entrevistado 3 & 10 anos \\
\hline Entrevistado 4 & 30 anos \\
\hline Entrevistado 5 & 36 anos \\
\hline Entrevistado 6 & 22 anos \\
\hline Entrevistado 7 & 19 anos \\
\hline Entrevistado 8 & 8 anos \\
\hline
\end{tabular}

Fonte: dados de pesquisa.

As respostas permitiram a descoberta e a exploração do problema que levou em conta a abordagem relativa ao processo decisório de Mintzberg, Raisinghani e Théorêt (1976) e o DNP destacado por Rozenfeld et al. (2006), por serem estas literaturas mais apropriadas ao tipo de negócio estudado e às características dos atores envolvidos.

O tratamento e a análise dos dados foram conduzidos por meio da análise de conteúdo (categorização), segundo Bardin (2009). De acordo com a autora, a categorização é utilizada para estabelecer as relações entre as variáveis, as quais surgiram da bibliografia consultada: processo decisório e desenvolvimento de novos produtos. Ainda, conforme Bardin (2009), a análise de conteúdo é um agrupamento de técnicas por meio da descrição objetiva, sistemática e quantitativa do conteúdo manifesto das comunicações, cuja finalidade é a sua interpretação. Deste modo, a categorização tem como primeiro objetivo fornecer, por condensação, uma representação simplificada dos dados brutos (BARDIN, 2009).

A análise consistiu em descobrir os núcleos de sentido que apoiam o objetivo do estudo e foi estruturada em três etapas: (i) pré-análise; (ii) exploração do material e (iii) tratamento dos resultados, inferência e interpretação. A partir das entrevistas, houve o processo de divisão, classificação e ordenação das palavras de acordo com a sua aderência aos significados das perguntas do roteiro. A partir da análise dos dados e da sua relação com o referencial teórico, discorre-se sobre os principais pontos revelados pela investigação e faz-se a discussão dos resultados da pesquisa.

\section{ANÁLISE E DISCUSSÃO DOS RESULTADOS}

Após a transcrição das entrevistas, procedeu-se à análise das categorias definidas a partir dos objetivos geral e específicos subsidiados nos dois temas centrais: processo de decisão e processo de DNP tal como acontece na cooperativa. As análises referem-se às categorias que sumarizam as ideias manifestadas nas entrevistas e os trechos das falas dos entrevistados serão identificados como E1, E2, E3, E4, E5, E6, E7 e E8, sendo o "E” uma identificação para "entrevistado" e o número, a ordem das entrevistas. 


\subsection{ROTINA DOS PROCESSOS}

O processo de tomada de decisão na cooperativa em relação ao lançamento de um produto não é formalizado e acontece a partir da identificação de uma demanda de mercado, tal como presente na primeira fase descrita por Mintzberg, Raisinghani e Théorêt (1976). Para E2, "não há um modelo pré-definido de tomada de decisão, porque cada situação exige uma postura", mas a palavra final fica a cargo da diretoria.

Fazemos estudo com o pessoal de campo, depois que tiver tudo analisado, a gente leva para diretoria nossa. Para a superintendência, que encaminha para a diretoria. Eles que tomam a decisão se vai lançar ou não.

Esta falta de modelo a ser seguido também está presente no DNP, o que pode ser sentido na fala de E4: "a gente vai vendo o que é necessário e passa para a diretoria". Embora Mattar e Santos (2003, p. 320) indiquem que não há "um padrão único para a estruturação do processo de desenvolvimento de novos produtos", é possível verificar pelas entrevistas que a falta de um "modelo" acaba por tornar o processo mais demorado e à mercê da diretoria, independentemente das etapas anteriores. Ou seja, ainda que todo o estudo indique o lançamento de um produto, o fato deste não surgir do planejamento estratégico pode vir a ser abortado na etapa final, desprezando todos os esforços anteriores. Neste sentido, é importante trazer a fala de Rozenfeld et al. (2006), que destacam a necessidade da empresa ter um modelo sistematizado e documentado de cada etapa do processo para permitir às empresas maior mobilidade diante da concorrência. Para E5,

O modelo atual normalmente acontece em função da demanda do mercado. Como que as coisas acontecem normalmente? Como eu tenho vários representantes no mercado, todos esses negócios eu tenho representante que está atendendo o mercado, ele está no campo no dia a dia, vendendo.

O entrevistado E1 dá uma ideia dos riscos ocasionados pela falta de um roteiro, tal como o desperdício de esforços e recursos:

Normalmente tem situação que você tem que fazer isso com mais cuidado, mais cautela, não adianta. Porque às vezes você está fazendo um estudo de um produto novo, mas de repente ele não... chega lá na frente, fala: não é viável.

Estes apontamentos dão conta de que há uma lacuna entre a prática da cooperativa e as etapas descritas por Rozenfeld et al. (2006), na macrofase do pré-desenvolvimento de um produto, uma vez que os novos itens que serão incorporados ao portfólio não partem de uma decisão global contemplada no planejamento estratégico, mas respondem à instantaneidade do mercado, por meio do feeling da equipe de vendas. 


\subsection{DECISÃO NO DESENVOLVIMENTO DO PRODUTO}

A partir de uma necessidade identificada no mercado, passa-se a analisar a viabilidade do DNP por meio de etapas que fazem parte da macrofase de desenvolvimento descritas por Rozenfeld et al. (2006), contemplando as principais decisões de projeto. Inicia-se esta fase com o projeto informacional, que envolve a busca de informações, investigação e disseminação do andamento do processo. Verifica-se que esta etapa na empresa estudada é bastante tímida, reduzida a informações de mercado coletadas por representantes comerciais e investigação apenas de como outras empresas se comportam. Mesmo observando que há uma deficiência na etapa informacional, o produto a ser lançado passa por testes, verificação de capacidade produtiva e recursos necessários para a comercialização, como pode ser observado nas falas abaixo:

Então é gente que te ajuda, né, vem com ideias, acompanha toda a fase de testes, né, de acompanhamento, de estudo mesmo, de viabilidade daquele produto (E1).

Muitos produtos que nós vamos lançar, os cooperados nos ajudam nesse lançamento com os testes desse produto. Então nós sempre testamos isso. A cooperativa tem o CTC, que é o Centro Tecnológico, onde nós temos uma área destinada a testes (E4).

A gente faz uns testes primeiramente, e depois que os testes são avaliados e são executados, aí sim a gente manda para o comercial, pra gente efetuar, possivelmente, uma venda (E8).

Quanto às etapas do projeto conceitual e projeto detalhado da macrofase do desenvolvimento, os entrevistados afirmam que elas existem:

Quando a gente tem essa demanda, a gente traz, apresenta, isso segue um caminho, que é do estudo daquele produto, daquele processo para fabricar esse produto, ou para se adquirir esse produto. Em seguida, viabilidade, passa por estudo de viabilidade econômica, e depois ele segue, principalmente para as pessoas das áreas envolvidas (E6).

Depois da identificação no mercado, você segue outros passos: pesquisas de preço, custo de produção e viabilidade, ver se tem viabilidade ou não. E vê o que tem no mercado hoje. Se o mercado já está saturado, se não está, se é inovação, se tem várias indústrias fazendo, produzindo isso, se não tem, como que está, sem tem condições de fazer um produto melhor do que está no mercado (E8).

Mas, de todas as etapas, a comercialização recebe amplo destaque por parte dos entrevistados que apontam-na como o grande gargalo para o sucesso do produto.

Tudo que a gente solta aqui... o cuidado que a gente tem que ter é para não lançar um produto que não tenha sucesso no mercado (E1).

A primeira providência é pôr no mercado, este é o gargalo de todo o processo. Lançar um produto hoje, colocar no mercado. Você produzir um produto hoje não é tão difícil (E2).

Então é essa comunicação, você conseguir mostrar essa novidade para o mercado. Ó, eu tenho um produto que é diferente. Eu tenho um produto que faz um algo a mais. Eu tenho uma novidade, mesmo, né, é [...] mostrar isso para o mercado (E4). 
Então as dificuldades que a cooperativa tem hoje é no varejo. Tudo que é lançamento de produto que nós víamos necessidade de estar integrando isso no mercado, melhorando, vamos supor, a quantidade de produtos ofertados, a gente se depara com problema de varejo, que a cooperativa não é muito especialista nisso. Tanto que ela está agora investindo maciçamente nessa área, né, contratando área de marketing, outras áreas, para conseguir melhorar nesse aspecto de varejo (E5).

A preocupação generalizada dos entrevistados com a comercialização pode ser entendida como consequência da debilidade dos processos de lançamento de produtos não serem contemplados dentro das macroestratégias organizacionais, como indicam Rozenfeld et al. (2006). Todo o processo é iniciado com uma leitura do mercado por parte dos vendedores e técnicos, embasados em sondagens empíricas que subsidiam a etapa de desenvolvimento.

De uma forma geral, as decisões da cooperativa caracterizam-se pela observância às "decisões não estruturadas" de Mintzberg, Raisinghani e Théorêt (1976), uma vez que acontecem conforme as necessidades vão surgindo. Em relação à macrofase do desenvolvimento descritas por Rozenfeld $e t$ al. (2006), embora as etapas sejam observadas na cooperativa, elas também poderiam ser enquadradas como "não estruturadas" porque são realizadas de acordo com o momento.

\subsection{PÓS-DESENVOLVIMENTO}

As deficiências observadas nas macrofases do pré-desenvolvimento e no desenvolvimento de produtos, destacadas por Rozenfeld et al. (2006), acabam por respingar no setor de comercialização que é entendido quase que unanimemente pelos entrevistados como o responsável pelo fracasso de determinados produtos e a consequente saída deles do mercado. Os recortes abaixo dão uma ideia desta percepção:

Você produzir um produto hoje, não é tão difícil. Não vejo dificuldade. Agora, você pegar um produto aqui e lançar no mercado, isso, no meu ponto de vista, é o difícil hoje (E2).

O nosso grande problema mesmo se chama comercial. Esse trabalho lá na gôndola, na prateleira, e o problema da concorrência. Apesar da marca, você... os outros também têm marca, né. Então hoje o grande desafio da cooperativa é de fora pra dentro. A parte interna da cooperativa ela tem hoje todos os recursos, laboratórios, ela tem tudo montado pra fazer um produto bom (E5).

A facilidade, para mim, é essa, a produção. Agora, o maior gargalo, no meu ponto de vista, é o mercado, você introduzir o produto (E7).

A retirada dos produtos ocorre sem, no entanto, se ter uma identificação clara de onde se deu o erro. Em outra frente, identifica-se pelos entrevistados que a etapa de acompanhamento do produto se faz tão somente pelo desempenho de vendas. Mesmo considerando que as etapas do pós-desenvolvimento existem nos processos da cooperativa, é a comercialização responsável pelo fracasso ou baixo desempenho de um lançamento. 


\subsection{OS MÚLTIPLOS INTERESSES}

Os múltiplos papéis desempenhados pelos cooperados: proprietários, clientes, fornecedores (BARREIROS; PROTIL; MOREIRA, 2008) e, ainda, gestores e investidores sociais, permeiam todas as etapas de decisão e DNP. Como clientes e proprietários que visam resultados, os cooperados

levam informações. Por exemplo: olha, a empresa tal já tem um produto assim. Vocês têm alguma coisa parecida? Então quando a gente não tem algo assim, nós vamos atrás. Buscamos atrás no mercado, vemos. Aí sim, depois de testes avaliados, a gente põe pra ele como venda (E8).

Para o entrevistado E3, este envolvimento é maior como fornecedor porque,

quando ele está na safra, ele é fornecedor, e é muito difícil de se tratar com ele, quando ele é fornecedor. Porque ele passa a ser o dono da matéria-prima, [...] ele passa a ter o poder, confia mais, ele exige mais. Agora, quando ele passa a ser cliente, quando ele precisa do adubo, do fertilizante, entra a concorrência e aí ele vai brigar por preço. Então eu acho que quando ele está no papel de fornecedor, é mais complicado de se lidar com ele.

Mintzberg, Raisinghani e Théorêt (1976) destacam no processo de decisão a presença da rotina política, na qual os indivíduos acabam por satisfazerem interesses pessoais. Embora os entrevistados desviem deste assunto, verifica-se que o maior peso nestes múltiplos papéis é dos gestores, especificamente no caso da diretoria que, como cooperados, exercem a palavra final quanto às decisões e lançamento de produtos. $\mathrm{O}$ entrevistado $\mathrm{E} 7$ destaca o aspecto político presente no processo de lançamento de produtos:

O aspecto político pesa muito nas relações dos papéis. Questão de... até por questão de estrutura da empresa, uma área que interfere na outra, de um na outra, e por aí vai... Por exemplo, muitas vezes uma decisão que poderia ser tomada com trinta dias talvez saia com quarenta, sessenta.

Mesmo abaixo da diretoria, diversos executivos envolvidos nas etapas de decisão ou DNP são cooperados, o que talvez explique a fala do entrevistado E7. Um cooperado com poder de decisão em determinada etapa pode antecipar ou retardar uma decisão em função do seu interesse como fornecedor de matéria-prima. O que fica evidente e se destaca nas entrevistas é que o julgamento das alternativas, tal como prescrevem Mintzberg, Raisinghani e Théorêt (1976), é de exclusividade de um nível hierárquico superior ao dos entrevistados. Embora toda a identificação e levantamento de informações sejam realizados pelos executivos das áreas, a decisão segue para o topo da pirâmide, onde podem ocorrer as grandes interferências em função dos interesses relacionados a um ou mais papéis desempenhados.

Um outro papel desempenhado pelos cooperados, o social, é citado pelos entrevistados timidamente: 
O que a gente tem vistoé que assim, gestores como o nosso, por exemplo, têmo desenvolvimento como algo muito forte, ele carrega isso, desenvolvimento social, desenvolvimento regional, e tudo. Mas assim, ele tem aquele empresário também, senão a gente não estaria onde a gente está hoje, enfim. Mas assim, eu acho que mais... acho que o social... acho que é a característica maior, eu acho (E7).

O que se vê é que o cooperado está interessado nos resultados individuais em todo tipo de interação com a cooperativa. Qualquer que seja o papel que esteja desempenhando, o que prevalece é o de dono e como tal exige o melhor preço quando vai vender, o melhor preço quando vai comprar. Isto fica claro nas falas dos entrevistados.

Os filhos de cooperados que vão se tornando cooperados também, eles já são meio imediatistas, eles já querem o resultado no bolso. Estou comprando um produto, porque eu quero um retorno porque eu estou entregando. Eu quero um retorno porque eu mereço, né? (E3).

Olha, eu acho que pesa a parte dele ser cooperado mesmo, dele ser dono. Então ele quer que a cooperativa atenda as necessidades dele, né. Que ele consiga vender o produto dele, como cliente, né, que ele consiga vender o produto dele, seja soja, milho, o que for, leite, que a cooperativa consiga pra ele o melhor preço possível (E4).

Então eu acho que prevalece a característica de investidor dele. Então assim, e o que isso vai retornar economicamente para ele. Porque eu acho que esse pensamento social... eu nem digo social, mas assim, esse pensamento coletivo, cooperativista, a cooperativa tem isso muito forte, mas o que a gente nota é que os cooperados [...] principalmente quem tem chegado por último, ele não prefere a cooperativa pelo bem que ela faz aos outros, ele prefere porque é interessante para ele. Então, claro que chega no final, isso tudo faz parte de um bolo e que, querendo ou não, isso serviu para desenvolvimento de todos (E6).

Embora os múltiplos papéis dos cooperados sejam manifestados, o social é o que menos desponta, sobressaindo claramente em todos eles o interesse pelo ganho individual, provocando grandes implicações políticas na gestão diária. Estes apontamentos permitem inferir que, em última instância, a forma de propriedade das organizações, se pública, privada ou sem fins lucrativos, pouco importa quando estão em jogo o ganho, cada qual tem como foco os resultados individuais.

\section{CONCLUSÃO}

As cooperativas desempenham importante papel no setor de agronegócios, auxiliando os produtores nas diversas frentes para a produção e comercialização de seus produtos. Como organização civil/comercial sem fins lucrativos, tem como propósito fundamental gerar benefícios para seus associados, capacitando-os para o trabalho e a vida em comunidade. No entanto, os relacionamentos e interesses são diferentes conforme o papel desempenhado na relação cooperado-cooperativa.

Com este ambiente posto, a proposta central deste estudo foi verificar como se dá o processo de decisão no desenvolvimento de produtos em uma cooperativa, considerando-se que os cooperados atuam como proprietário, cliente, fornecedor, gestor e investidor social concomitantemente. Para entender estas relações e processos, foram entrevistados oito executivos da empresa que estão diretamente ligados às atividades de lançamento de produtos e tomada de decisão. 
Os resultados demonstram que a falta de protocolo permeia todo o processo de decisão e DNP, sendo este o fato que desencadeia e sustenta o não cumprimento às demais etapas prescritas pela literatura. Ainda, em relação à padronização das rotinas, não são formalizadas e nem há um modelo a ser seguido pelos executivos que decidem ao passo dos acontecimentos, ficando evidente que a falta de arquétipo não dá celeridade ao lançamento de produtos, prejudicando a atuação da cooperativa no mercado.

No quesito "processo de decisão", a prática da cooperativa caracteriza-se por "decisões não estruturadas", conforme as colocações de Mintzberg, Raisinghani e Théorêt (1976), em que as etapas vão sendo realizadas de acordo com as demandas, em um movimento cíclico com a sobreposição de fases.

O desenvolvimento de produtos da cooperativa também adota uma sequência de atividades não estruturadas, mas que aqui é prejudicial por envolver mais recursos estratégicos. O primeiro apontamento, além da falta de padrão formal para o processo, é que a definição de DNP não parte do planejamento estratégico, mas sim da identificação do mercado por meio de vendedores e solicitações de cooperados. Esta política demonstra que a cooperativa não trabalha com a inovação de produtos, preferindo a postura de imitação. Fica evidente também que as fases descritas por Rozenfeld et al. (2006) para DNP não fazem parte da rotina dos executivos. Elas até são realizadas por uma demanda natural, mas não estão dentro de uma linearidade que garanta a eliminação de falhas já na concepção do projeto e, ainda, evite o desperdício de esforços e recursos e o lançamento de produto em não conformidade com as expectativas dos clientes.

A macrofase do pós-desenvolvimento é um elemento chave para os gestores da cooperativa que o colocam no topo da pirâmide. Todo sucesso ou insucesso do produto é atribuído à comercialização, o que demonstra claramente uma orientação para a venda. Acredita-se que o empenho da equipe de vendas é determinante para que os clientes comprem o produto que foi desenvolvido.

Os interesses pautados nos diferentes papéis dos cooperados são evidentes e convergem todos para o interesse individual voltado ao lucro em qualquer relação que mantêm com a cooperativa. De todos os papéis possíveis para os cooperados, o que menos aparece é o social, como possibilidade de benefícios mútuos para a vida em comunidade. Os benefícios acontecem, mas de ordem econômica individual. A constatação principal é que o caráter cooperativista da sociedade sem fins lucrativos pouco se aplica ao caso estudado.

Embora estes resultados pudessem ser esperados para o tipo de negócio, por este ainda carecer de um entusiasmo maior por processos de gestão menos empíricos, as conclusões apontadas não podem ser estendidas a outras cooperativas agropecuárias, uma vez que se tratou de estudo de um único caso. A título de indicação, entende-se ser possível ampliar os estudos junto a outras cooperativas do agronegócio, para outras organizações cooperativistas de segmentos diferentes e, ainda, de outros estados para verificar se os resultados apontados neste estudo se firmam ou não em outros ambientes. 


\section{REFERÊNCIAS}

BARDIN, L. Análise de Conteúdo. Tradução de Luís A. Reto e Augusto Pinheiro. 5ed. Lisboa: Edições 70, 2009.

BARREIROS, R. F.; PROTIL, R. M.; MOREIRA, V. R. Processo decisório nas cooperativas agroindustriais do Paraná: uma análise comparativa utilizando o modelo político e o modelo racional de decisão. Revista de Contabilidade e Organizações, v. 2, p. 1-15, 2008.

BATAGLIA, W. O processo decisório de investimento estratégico em tecnologia da informação. Dissertação de Mestrado. São Paulo: FEA-USP, 2002.

BATALHA, M. O. et al. Recursos humanos e agronegócio: a evolução do perfil profissional. Jaboticabal: Novos Talentos, 2005.

BETHLEM, A. de S. Modelos de processo decisório. Revista deAdministração, v. 22, n. 3, jul/set. 1987.

BILIBIO, C. Planejamento estratégico na empresa agrícola familiar. São Luís: Endufman, 2009.

CHOO, C. W. A organização do conhecimento. São Paulo: SENAC, 2003.

COSTA, A. I. A; JONGEN, W. M. F. New insights into consumer led food product development. Trends in Food Science \& Technology, v. 17, p. 457-465, 2006.

CRESWELL, JW. Projeto de pesquisa: métodos qualitativo, quantitativo e misto. São Paulo: Bookman/Artmed, 2010.

DAVILA, T. An empirical study on the drivers of management control systems design in new product development. Account, Organizations and Society, v. 25, p. 383409, 2000.

FACCIO, K.; SOARES ECHEVESTE, M.; PEREIRA KECHINSKI, C. RODRIGUES ROSA, 1. Análise do modelo de desenvolvimento de produto de uma empresa fabricante de produtos e soluções para o setor automotivo. Exacta, São Paulo, v.8, n. 1, p.81-88, 2010. Disponível em <http://www.redalyc.org/articulo.oa?id=81015201009>. Acesso em: 22 ago 2016.

GODOI, C.K.; MATTOS, P.L. de. Entrevista qualitativa: instrumento de pesquisa e evento dialógico. In: GODOI, C.K.; BANDEIRA-DE-MELLO, R.; BARBOSA DA SILVA, A. (orgs.). Pesquisa qualitativa em estudos organizacionais. São Paulo: Saraiva, 2006.

LENGLER, L; LAGO, A; CORONEL, D. A. A organização associativa no setor apícula: contribuições e potencialidades. Organizações rurais e agroindustriais. Lavras, 2007.

MATTAR, F. N.; SANTOS, D. G. dos. Gerência de produtos: como tornar seu produto um sucesso. São Paulo: Atlas, 2003. 
MINTZBERG H.; RAISINGHANI, D.; THÉORET, A. The structure of “unstructured” decision process. Administrative Science Quarterly, v. 21, 1976.

PATTON, M.Q. Qualitative research and evaluation methods. Thousand Oaks: Sage, 2002.

PETERS, A. J. ROONEY, E. M.; ROGERSON, J. H., MCQUATER, R.E.; SPRING, M.; DALE, B. G. New Product Design and Development: A Generic Model. The TQM Magazine, v. 11, n. 3, p. 172-179, 1999.

REIS, E.; LOBLER, M.L. O processo decisório descrito pelo indivíduo e representado nos sistemas de apoio à decisão. RAC, v.16, n.3, Curitiba, mai./jun. 2012.

ROZENFELD, H.; FORCELLINI, F.A.; AMARAL, D.C.; TOLEDO, J.C.; SILVA, S.L.; ALLIPRANDINI, D.H.; SCALICE, R.K. Gestão de Desenvolvimento de Produtos: uma referência para a melhoria do processo. São Paulo: Saraiva, 2006.

ULRICH, K.T. \& EPPINGER, S.D. Product Design and Development. Nova Iorque: McGrawHill, 2000.

VALOR ECONÔMICO. 1000 Maiores Empresas. Publicação anual Valor Econômico. $n^{\circ} 14$, ano 14, agosto 2014, p. 184 e 340. Disponível em <http://revistavalor.com.br/home. aspx ?pub=18\&edicao=7>. Acesso em: 20 ago 2014.

WHEELWRIGHT, S.C.; CLARK, K. B. Managing new product and process development: text and cases. New York: Free Press, 1994. 